may pioneer further studies investigating the usage of adipokines such as vaspin and lipocalin2 levels as biomarkers in the diagnose and disease course of PsA. Disclosure of Interest: None declared

DOI: 10.1136/annrheumdis-2018-eular.7237

\section{AB0902 EFFICACY OF TOFACITINIB BY BACKGROUND METHOTREXATE DOSE IN PATIENTS WITH PSORIATIC ARTHRITIS: A POST-HOC ANALYSIS OF POOLED DATA FROM 2 PHASE 3 TRIALS}

A.J. Kivitz ${ }^{1}$, O. FitzGerald ${ }^{2}$, P. Nash ${ }^{3}$, S. Pang ${ }^{4}$, V.F. Azevedo ${ }^{5}$, E. Kudlacz ${ }^{6}$ C. Wang ${ }^{6}$, D. Graham ${ }^{6}$, L. Takiya ${ }^{7}$. 'Department of Rheumatology, Altoona Center for Clinical Research, Duncansville, PA, USA; ${ }^{2}$ Department of Rheumatology, St Vincent's University Hospital, Dublin, Ireland; ${ }^{3}$ Department of Medicine, University of Queensland, St Lucia, Brisbane, Australia; ${ }^{4}$ St. Jude Medical Center, Fullerton, CA, USA; ${ }^{5}$ Universidade Federal do Paraná, Curitiba, Brazil; ${ }^{6}$ Pfizer Inc, Groton, $C T ;{ }^{7}$ Pfizer Inc, Collegeville, PA, USA

Background: Tofacitinib is an oral Janus kinase inhibitor for the treatment of psoriatic arthritis (PsA). The efficacy of tofacitinib has been evaluated in 2 Phase 3 studies in patients (pts) with PsA.

Objectives: To describe the efficacy of tofacitinib by background methotrexate (MTX) dose in pts with PsA.

Methods: This post-hoc analysis utilised efficacy data pooled from 2 Phase 3, randomised, double-blind, placebo-controlled studies (OPAL Broaden [12 months; NCT01877668] and OPAL Beyond [6 months; NCT01882439]) in pts with a diagnosis ( $\geq 6$ months) of active PsA ( $\geq 3$ swollen and $\geq 3$ tender joints). Pts in OPAL Broaden were tumour necrosis factor inhibitor (TNFi)-naïve and had an inadequate response (IR) to $\geq 1$ conventional synthetic disease-modifying antirheumatic drug (csDMARD). Pts in OPAL Beyond had an IR to $\geq 1 \mathrm{TNFi}$. Pts were randomised to tofacitinib 5 or $10 \mathrm{mg}$ twice daily (BID), placebo or adalimumab $40 \mathrm{mg}$ subcutaneous every 2 weeks (OPAL Broaden; adalimumab data not shown). All pts received a stable dose of 1 csDMARD (eg MTX, leflunomide or sulfasalazine) as background therapy. The maximum dose of MTX allowed per protocol was $20 \mathrm{mg} /$ week. Efficacy outcomes for tofacitinib at Month 3 were evaluated by background MTX dose ( $\leq 15$ vs $>15 \mathrm{mg} /$ week) and included: ACR20/ $50 / 70$ response rates ( $\geq 20 / 50 / 70 \%$ improvement from baseline, respectively), Health Assessment Questionnaire-Disability Index (HAQ-DI) response rate (reduction from baseline $>0.35$ points) and mean change from baseline in $\mathrm{HAQ}$ DI score. Analyses were based on the full analysis set for pts receiving MTX on Day 1 ; pts with missing data were considered as having a non-response for binary endpoints. No statistical testing was performed.

Results: In total, data from 556 pts who received tofacitinib plus MTX only or placebo plus MTX only (tofacitinib 5 mg BID, $n=186$; tofacitinib 10 mg BID, $n=178$; placebo, $n=192$ ) were included in this analysis. Most pts were treated with background MTX at doses $\leq 15 \mathrm{mg} /$ week ( $\mathrm{n}=371,66.7 \%$; mean [SD] dose, 12.6 [3.1] $\mathrm{mg} /$ week) vs $>15 \mathrm{mg} /$ week ( $\mathrm{n}=185,33.3 \%$; mean [SD] dose, 19.8 [0.8] mg/week). Baseline demographics and disease characteristics were generally similar between arms in MTX dose groups (table 1). At Month 3, tofacitinib 5 and $10 \mathrm{mg}$ BID were generally associated with numerically greater ACR and HAQ-DI response rates and greater changes from baseline in HAQ-DI score compared with placebo. The magnitude of tofacitinib effects on efficacy outcomes appeared broadly similar between background MTX dose groups (table 1).

Abstract AB0902 - Table 1. Patient demographics and disease characteristics at baseline, and efficacy outcomes at Month 3 by MTX dose

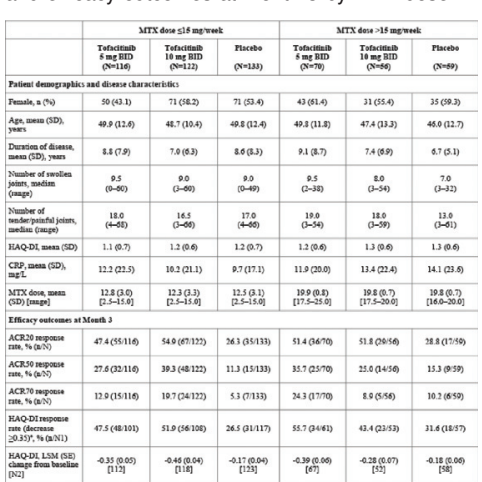

${ }^{*}$ Among pts with baseline HAQ-DI score $\geq 0.35$

Missing values for ACR20/50/70 response rates and $\mathrm{HAQ}-\mathrm{DI}$ response rate were considered as non-response to treatment

LSM were calculated based on a mixed model for repeated measures without imputation for missing values
The maximum permitted dose of MTX was $20 \mathrm{mg} /$ week

The analyses included all pts who received MTX as background therapy only on Day 1 in the FAS

ACR, American College of Rheumatology; BID, twice daily; CRP, C-reactive protein; FAS, full analysis set; HAQ-DI, Health Assessment Questionnaire-Disability Index; LSM, least squares mean; MTX, methotrexate; n, number of pts with response; $\mathrm{N}$, number of pts included in the analysis; $\mathrm{N} 1$, number of pts included in the HAQ-DI response analysis; N2, number of pts evaluable for change from baseline in HAQ-DI at Month 3; pts, patients; SD, standard deviation; SE, stand ard error

Conclusions: The results of this pooled analysis suggest that the efficacy of tofacitinib in pts with PsA was greater than placebo and does not differ when evaluated by background MTX dose ( $\leq 15 \mathrm{vs}>15 \mathrm{mg} /$ week), although small pt numbers in some groups may limit the conclusions that can be made. These results are consistent with findings from similar analyses of tofacitinib in pts with rheumatoid arthritis.

Acknowledgements: Study sponsored by Pfizer Inc. Medical writing support was provided by $\mathrm{C}$ Viegelmann of $\mathrm{CMC}$ and funded by Pfizer Inc.

Disclosure of Interest: A. Kivitz Consultant for: AbbVie, Celgene, Genentech, Genzyme, Janssen, Merck, Novartis, Pfizer Inc, Sanofi and UCB, Speakers bureau: AbbVie, Celgene, Genentech, Genzyme, Janssen, Merck, Novartis Pfizer Inc, Sanofi and UCB, O. FitzGerald Grant/research support from: AbbVie, BMS, Novartis, Pfizer Inc, Consultant for: Amgen, Celgene, Eli Lilly, Janssen, P Nash Grant/research support from: AbbVie, BMS, Eli Lilly, Janssen, Novartis Pfizer Inc, Roche, Sanofi, UCB, Consultant for: AbbVie, BMS, Eli Lilly, Janssen, Novartis, Pfizer Inc, Roche, Sanofi, UCB, Speakers bureau: AbbVie, BMS, El Lilly, Janssen, Novartis, Pfizer Inc, Roche, Sanofi, UCB, S. Pang: None declared, V. Azevedo Grant/research support from: AbbVie, Eli Lilly, Genentech, GSK Pfizer Inc, UCB, Consultant for: AbbVie, Merck-Serono, Novartis, Pfizer Inc Speakers bureau: AbbVie, Janssen, Merck-Serono, Novartis, Pfizer Inc, Sanofi, E. Kudlacz Shareholder of: Pfizer Inc, Employee of: Pfizer Inc, C. Wang Shareholder of: Pfizer Inc, Employee of: Pfizer Inc, D. Graham Shareholder of: Pfizer Inc, Employee of: Pfizer Inc, L. Takiya Shareholder of: Pfizer Inc, Employee of: Pfizer Inc DOI: 10.1136/annrheumdis-2018-eular.1278

\section{AB0903 EFFICACY OF TILDRAKIZUMAB IN ETANERCEPT PARTIAL OR NONRESPONDERS}

J. Crowley ${ }^{1}$, K.A. Papp ${ }^{2}$, C.-H. Hong ${ }^{3}$, J. Parno ${ }^{4}$, A.M. Mendelsohn ${ }^{4}$, Q. Li ${ }^{5}$, N. Cichanowitz ${ }^{5}$, C. La Rosa ${ }^{5}$. 1 Bakersfield Dermatology, Bakersfield, CA, USA; ${ }^{2}$ Probity Medical Research, Waterloo, ON; ${ }^{3}$ Department of Dermatology and Skin Science, University of British Columbia and Probity Medical Research, Surrey, BC, Canada; ${ }^{4}$ Sun Pharmaceutical Industries, Inc., Princeton, NJ; ${ }^{5}$ Merck and Co., Inc., Kenilworth, NJ, USA

Background: Etanercept (ETN) is an anti-tumour necrosis factor (TNF) medication that was among the first biologics approved for psoriasis. Additional medications have been developed or are in development for psoriasis, and patients who do not adequately respond to ETN may benefit from these more recent biologics. Objectives: Here we report the efficacy of tildrakizumab (TIL), a humanised antiIL-23p19 monoclonal antibody, as evaluated in patients with moderate to severe chronic plaque psoriasis who were partial (Psoriasis Area and Severity Index $[P A S I] \geq 50-<75$ ) or nonresponders (PASI $<50$ ) to ETN and subsequently rerandomized to TIL in the phase 3 reSURFACE 2 trial (NCT01729754).

Methods: Patients with psoriasis ( $\geq 10 \%$ body surface area, Physician's Global Assessment $[P G A]$, and PASI $\geq 12$ ) participated in reSURFACE 2, a 3-part, 52 week, randomised controlled trial. In Part 1 (Weeks 0-12), patients were randomised to subcutaneous TIL $200 \mathrm{mg}$, TIL $100 \mathrm{mg}$, or placebo (PBO) administered at Weeks 0 and 4, or ETN 50 mg administered twice weekly. In Part 2 (Weeks 12 28), TIL and ETN patients remained on the same treatment (TIL administered at Week 16; ETN once weekly), whereas PBO patients were rerandomized to TIL 100 or 200 mg. In Part 3 (Weeks 28-52), ETN responders (PASI >75) were discontinued, and partial and nonresponders were switched to TIL 200 mg (administered at Weeks 32, 36, and 48). For this post hoc analysis, the proportion of patients $( \pm S D$ ) with PASI response and PGA response (score of 0 [clear] or 1 [minimal] with at least a 2-grade score reduction from baseline) were determined at Week 52. Primary results from the trial have been previously reported. ${ }^{1}$

Results: In total, 1090 patients were randomised. Of the 313 patients randomised to ETN, by Week 28 there were 83 partial responders and 39 nonresponders. At Week 52 (after 20 weeks of TIL treatment) for ETN partial responders, $75 \% \pm 5 \%$, $34 \% \pm 5 \%, 15 \% \pm 4 \%$, and $58 \% \pm 5 \%$ had achieved PASI $75,90,100$, and PGA response of $0 / 1$, respectively, with TIL $200 \mathrm{mg}$ treatment. At Week 52 for ETN nonresponders, $54 \% \pm 6 \%, 31 \% \pm 5 \%, 10 \% \pm 3 \%$, and $56 \% \pm 5 \%$ had achieved PAS $75,90,100$, and PGA response of 0/1, respectively, with TIL $200 \mathrm{mg}$ treatment. Adverse events were similar in patients switched from ETN to TIL at Week 28 compared with the patients who were maintained on TIL through Week 52. 
Conclusions: A substantial portion of patients with moderate to severe chronic plaque psoriasis who were partial or nonresponders to ETN may respond after switching to treatment with TIL $200 \mathrm{mg}$. TIL may be a reasonable option for those who do not achieve adequate response to ETN.

\section{REFERENCE:}

[1] Reich, et al. Lancet. 2017;390(10091):276-288.

Acknowledgements: This study was funded by Merck and Co., Inc. Editorial support for abstract submission was provided by Fishawack Communications and funded by Sun Pharmaceutical Industries, Inc. Analyses were presented at the American Academy of Dermatology. Annual Meeting, San Diego, California, USA, 2018

Disclosure of Interest: J. Crowley Grant/research support from: Abbvie, Amgen, Sun Pharma, Lilly, Novartis, Janssen, Regeneron, Sanofi, Merck, Pfizer, Sandoz, MC2 Therapeutics, Verrica, Consultant for: Abbvie, Sun Pharma, Dermira, Lilly, Novartis, Celgene, Speakers bureau: Abbvie, Lilly, Novartis, Regeneron, Sanofi, K. Papp Grant/research support from: AbbVie, Akros, Amgen, Anacor, Boehringer Ingelheim, Celgene, Dermira, Eli Lilly, EMD Serono, Janssen, Kyowa Hakko Kirin, Meiji Seika Pharma, Merck SharpDome, Mitsubishi Pharma, Novartis, Pfizer, UCB, Valeant, Consultant for: AbbVie, Akros, Amgen, Anacor, Boehringer Ingelheim, Celgene, Dermira, Eli Lilly, EMD Serono, Janssen, Kyowa Hakko Kirin, Meiji Seika Pharma, Merck SharpDome, Mitsubishi Pharma, Novartis, Pfizer, UCB, Valeant, Speakers bureau: AbbVie, Amgen, Celgene, Eli Lilly, Janssen, Kyowa Hakko Kirin, Novartis, Pfizer, UCB, Valeant, C.-H. Hong Grant/ research support from: Amgen, Abbvie, Eli Lilly, Janssen, Merck, Novartis, GlaxoSmithKline, Celgene, UCB, Consultant for: Amgen, Abbvie, Eli Lilly, Janssen, Novartis, GlaxoSmithKline, Celgene, Sun Pharma, Speakers bureau: Amgen, Abbvie, Eli Lilly, Janssen, Novartis, Celgene, J. Parno Employee of: Sun Pharmaceutical Industries, Inc., A. Mendelsohn Employee of: Sun Pharmaceutical Industries, Inc., Q. Li Employee of: Merck Sharp and Dohme Corp., a subsidiary of Merck and Co., Inc., Kenilworth, NJ, USA, N. Cichanowitz Shareholder of: Merck and Co., Inc., Employee of: Merck Sharp and Dohme Corp., a subsidiary of Merck and Co., Inc., Kenilworth, NJ, USA, C. La Rosa Employee of: Merck Sharp and Dohme Corp., a subsidiary of Merck and Co., Inc., Kenilworth, NJ, USA

DOI: 10.1136/annrheumdis-2018-eular.6758

\section{AB0904 CORRELATION OF RAPID3 AND PROMIS10 IN PATIENTS WITH PSORIATIC ARTHRITIS}

A. Ogdie ${ }^{1}$, W.B. Nowell ${ }^{2}$, E. Applegate ${ }^{2}$, K. Gavigan ${ }^{2}$, S. Venkatachalam ${ }^{2}$, M. de la Cruz $^{3}$, E. Flood ${ }^{3}$, E.J. Schwartz ${ }^{3}$, B. Romero ${ }^{3}$, P. Hur ${ }^{4}{ }^{1}$ Perelman School of Medicine at the University of Pennsylvania, Philadelphia; ${ }^{2}$ Global Healthy Living Foundation, Upper Nyack; ${ }^{3}$ ICON, Gaithersburg; ${ }^{4}$ Novartis Pharmaceuticals Corporation, East Hanover, USA

Background: In addition to clinician assessment and laboratory tests, patientreported outcomes (PROs) are important for managing and improving the quality of care in patients with psoriatic arthritis (PsA). The RAPID3 was originally developed for use in patients with rheumatoid arthritis, but it may be used in clinical practice to assess disease activity in patients with PsA. ${ }^{1}$ The PROMIS10 is a general (nondisease-specific) PRO instrument that measures physical, mental, and social health. ${ }^{2}$ Developed for the general population, PROMIS10 has not yet been specifically validated in PsA.

Objectives: To evaluate the relationship between RAPID3 and PROMIS10 in patients with PsA.

Methods: US adults with a self-reported diagnosis of PsA were recruited through CreakyJoints (www.CreakyJoints.org), an online patient support community comprising patients with arthritis and arthritis-related diseases and their caregivers. Respondents completed an online survey that was designed to collect data on socio-demographics and clinical symptoms and included the RAPID3 and PROMIS10 to evaluate disease activity and health-related quality of life (HRQL), respectively. The RAPID3 consists of three patient self-reported scores (0-10): functional impairment, pain, and patient global assessment; total score$s \leq 3.0=$ near remission, 3.1 to $6.0=$ low disease severity, 6.1 to $12.0=$ moderate disease severity, and $\geq 12.1$ = high disease severity. PROMIS10 is a 10-item survey measuring physical and mental domains; individual scores are transformed to Tscore distributions normalised to the general population. PROMIS10 individual scores and global physical and mental health T-scores were stratified by RAPID3 disease severity and compared across RAPID3 severity levels using KruskalWallis or ANOVA tests, respectively. Spearman's correlation coefficient was calculated between RAPID3 total score and the PROMIS10 physical health and mental health T-scores, respectively.

Results: Among 203 respondents, the mean (SD) age was 51.6 (10.8) years and $172(84.7 \%)$ were female. The mean (SD) cumulative RAPID3 score was 14.7 (5.8) with mean (SD) functional impairment, pain tolerance, and patient's global estimate scores of $3.3(1.8), 6.0$ (2.3), and 5.4 (2.5), respectively. Patients' mean (SD) PROMIS10 global physical and mental health T-scores were 36.4 (7.3) and
40.2 (9.3), respectively. The mean individual domain scores and global T-scores worsened with increasing RAPID3 disease severity levels (all $p<0.001$ ) (table 1). PROMIS10 physical and mental health T-scores showed a strong $\left(r_{s}=-0.84\right)$ and moderate correlation $\left(r_{\mathrm{s}}=-0.57\right)$ with RAPID3, respectively.

Abstract AB0904 - Table 1. PROMIS10 Scores and Impact of PsA on Work by RAPID3 Disease Activity in Patients with PsA

\begin{tabular}{|l|c|c|c|c|c|}
\hline & \multicolumn{5}{|c|}{ RAPID3 Disease Activity } \\
\hline & $\begin{array}{c}\text { Near } \\
\text { Remission }\end{array}$ & $\begin{array}{c}\text { Low } \\
\text { Severity }\end{array}$ & $\begin{array}{c}\text { Moderate } \\
\text { Severity }\end{array}$ & $\begin{array}{c}\text { High } \\
\text { Severity }\end{array}$ & P value \\
\hline $\begin{array}{l}\text { PROMIS10 domain, } \\
\text { mean (SD) }\end{array}$ & $n=5$ & $n=14$ & $n=45$ & $n=139$ & \\
\hline Overall health & $3.60(0.55)$ & $2.93(0.73)$ & $2.87(0.69)$ & $2.10(0.73)$ & $<0.0001$ \\
\hline Quality-of-life & $4.20(0.84)$ & $3.07(0.83)$ & $3.16(0.74)$ & $2.29(0.89)$ & $<0.0001$ \\
\hline Physical health & $3.60(0.55)$ & $2.79(0.89)$ & $2.73(0.62)$ & $1.97(0.73)$ & $<0.0001$ \\
\hline Mental health & $4.40(0.55)$ & $3.14(1.10)$ & $3.11(1.05)$ & $2.63(1.10)$ & 0.0004 \\
\hline $\begin{array}{l}\text { Satisfaction with } \\
\text { social } \\
\text { activities/relationships }\end{array}$ & $4.20(0.45)$ & $3.00(0.96)$ & $3.09(1.06)$ & $2.06(1.09)$ & $<0.0001$ \\
\hline $\begin{array}{l}\text { Ability to carry out } \\
\text { every day physical } \\
\text { activities }\end{array}$ & $4.80(0.45)$ & $4.36(0.63)$ & $3.80(0.73)$ & $2.68(0.76)$ & $<0.0001$ \\
\hline Emotional distress & $4.80(0.45)$ & $3.43(1.16)$ & $3.16(0.80)$ & $2.65(1.00)$ & $<0.0001$ \\
\hline Fatigue & $4.00(1.00)$ & $3.50(0.65)$ & $3.04(0.71)$ & $2.25(0.76)$ & $<0.0001$ \\
\hline Pain & $4.20(0.45)$ & $3.93(0.27)$ & $3.38(0.49)$ & $2.40(0.56)$ & $<0.0001$ \\
\hline $\begin{array}{l}\text { Global physical health } \\
\text { T-score }\end{array}$ & $52.84(3.07)$ & $46.66(3.69)$ & $42.35(4.54)$ & $32.91(5.06)$ & $<0.0001$ \\
\hline $\begin{array}{l}\text { Global mental health } \\
\text { T-score }\end{array}$ & $58.44(5.86)$ & $45.17(7.60)$ & $44.84(7.53)$ & $37.50(8.56)$ & $<0.0001$ \\
\hline
\end{tabular}

PROMIS10, Patient-Reported Outcome Management Information System Global Health short form; RAPID3, Routine Assessment of Patient Index Data 3.

* Disease severity classified by RAPID3 scores: $\leq 3.0=$ near remission; 3.1 to $6.0=$ low severity; 6.1 to $12.0=$ moderate severity; $\geq 12.1=$ high severity.

Conclusions: RAPID3 and PROMIS10 physical health T-scores were strongly correlated in patients with PsA. PROMIS10 mental health scores moderately correlated with RAPID3, suggesting the mental health questions add a different construct. PROMIS10 and RAPID3 are relatively short questionnaires that can be used in the real world to track and monitor disease symptoms and HRQoL in patients with PsA.

\section{REFERENCES}

[1] Orbai A-M, Ogdie A. Rheum Dis Clin North Am. 2016;42(2):265-83.

[2] Hays RD, et al. Qual Life Res. 2009;18(7):873-80.

Acknowledgements: This study was sponsored by Novartis Pharmaceuticals Corporation, East Hanover, $\mathrm{NJ}$.

Disclosure of Interest: A. Ogdie Grant/research support from: Pfizer and Novartis, Consultant for: Abbvie, BMS, Eli Lilly and Company, Novartis, Takeda, and Pfizer, W. B. Nowell Employee of: Global Healthy Living Foundation, E. Applegate: None declared, K. Gavigan Employee of: Global Healthy Living Foundation, S. Venkatachalam Employee of: Global Healthy Living Foundation, M. de la Cruz Employee of: ICON, E. Flood Employee of: ICON, E. Schwartz Employee of: ICON, B. Romero Employee of: ICON, P. Hur Employee of: Novartis Pharmaceuticals Corporation

DOI: 10.1136/annrheumdis-2018-eular.5048

\section{AB0905 LONG-TERM (5-YEAR) EFFICACY AND SAFETY OF APREMILAST MONOTHERAPY IN DMARD-NAÏVE SUBJECTS WITH ACTIVE PSORIATIC ARTHRITIS}

A.F. Wells ${ }^{1}$, C.J. Edwards ${ }^{2}$, A.J. Kivitz ${ }^{3}$, P. Bird ${ }^{4}$, B. Guerette ${ }^{5}$, N. Delev ${ }^{5}$ M. Paris ${ }^{5}$, L. Teng ${ }^{5}$, J.A. Aelion ${ }^{6}{ }^{1}$ Rheumatology and Immunotherapy Center, Franklin, USA: ${ }^{2}$ University Hospital Southampton, Southampton, UK; ${ }^{3}$ Altoona Center for Clinical Research, Duncansville, USA; ${ }^{4}$ Combined Rheumatology Practice, Kogarah, Australia; ${ }^{5}$ Celgene Corporation, Summit, ${ }^{6}$ West Tennessee Research Institute, Jackson, USA

Background: Apremilast (APR) is an oral phosphodiesterase 4 inhibitor that helps regulate the immune responses that cause joint inflammation and other manifestations of psoriatic arthritis (PsA), including skin disease. 